$1-1-1930$

\title{
Standardization of Cherry and Blackberry Preserves and Blackberry Jelly
}

Hazel C. Cameron

Ruth B. Burns

Follow this and additional works at: https://researchrepository.wvu.edu/ wv_agricultural_and_forestry_experiment_station_bulletins

\section{Digital Commons Citation}

Cameron, Hazel C. and Burns, Ruth B., "Standardization of Cherry and Blackberry Preserves and Blackberry Jelly" (1930). West Virginia Agricultural and Forestry Experiment Station Bulletins. 234.

https://researchrepository.wvu.edu/wv_agricultural_and_forestry_experiment_station_bulletins/235 @ WVU. It has been accepted for inclusion in West Virginia Agricultural and Forestry Experiment Station Bulletins by an authorized administrator of The Research Repository @WVU. For more information, please contact ian.harmon@mail.wvu.edu. 


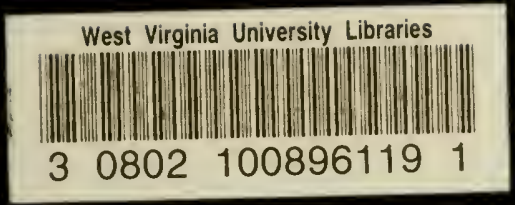




\section{West Virginia University Library}

This book is due on the date indicated below.

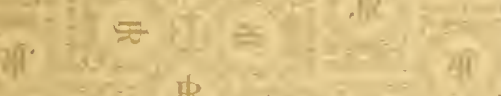


Digitized by the Internet Archive in 2010 with funding from

Lyrasis Members and Sloan Foundation 


\section{Standardization of Cherry and}

Blackberry Preserves and

\section{Blackberry Jelly}

by HAZEL CAMERON and RUTH B. BURNS 


\section{LITERATURE CITED}

(1) Association Official Agricultural Chemists.

1925. OFFicial and teNTATIVE METHOds OF aNALYsis. Ed. 2.

(2) Cruess, W. V.

1924. COMMERCIAL FRUIT AND VEgetable products. Ed. 1, 2nd impression. New York.

(3) —, AND MCNaIR, J. B.

1916. Jeilly investigations. Jour. Ind. and Eng. Chem. 8:417.

(4) Goldthwaite, N. E.

1909. PRINCIPLES of JELly MAKiNg. Jour. Ind. and Eng. Chem. 1:333.

(5)

1910. PRINCIPLES OF JELlY MAKING. Jour. Ind. and Eng. Chem. 2:457.

(6)

1914. PRINCIPLES OF JELLY MAKING. Univ. of Ill. Bul. 31, vol. xi.

(7)

1925. PRinciples of Making fruit Jellies. Col. Agr. Exp. Sta. Bul. 298

(8) Myers, P. B., And Baker, G. L.

1926. Fruit Jeli.ies. iv. The role of Salts. Del. Agr. Exp. Sta. Bul. 144, Tech. No. 7.

(9) MCNaIR, J. B.

1916. Consistency of Pectin Jells. Jour. Phys. Chem. 20:633.

(10) Nelson, E. K.

1925. Non-volatile acids of Blackberries. Jour. Amer. Chem. Soc. 47:568.

(11) Singh, L.

1922. A STUdy OF PECTIN AND ACIDITy in Jelly Making. Jour. Ind. and Eng. Chem. $14: 710$.

(12) TARR, L. W.

1923. Fruit Jellies. I. Role of acids. Del. Agr. Exp. Sta. Bul. 134, Tech. No. 2.

(13) - AND BAKER, G. L.

1924. fruit Jellies. II. ROle of sugar. Del. Agr. Exp. Sta. Bul. 136, Tech. No. 3.

(14)

1926. fruit Jellies. ili. Jelly strength measurements. Del. Agr. Exp. Sta. Bul. 142, Tech. No. 5 .

(15) United States Department of Agriculture.

1927. Service and regulatory announcements. Food and Drug No. 2.

(16)

1917. HOME CANNINg OF FRUits AND VEgetables. Farmers' Bulletin 853 .

1923. HOME MADE APPLE AND CITRUS PECTIN EXTRACTS AND THEIR USE IN JELLY MAKING. Dept. Circ. 254. 


\title{
Standardization of Cherry and Blackberry Preserves and Blackberry Jelly*
}

\author{
by HAZEL CAMERON and RUTH B. BURNS $\dagger$
}

THE MAKING of an ideal preserve or jelly is far from being standardized, either in the home or among commercial manufacturers. One reason lies in the complexity of the problem involved in the jellying or thickening of fruit juices, including as it does the colloid chemistry of the little-understood pectic substances. The present investigation was undertaken with the aim not of studying the underlying scientific principles, but of arriving as speedily as possible at a satisfactory method for cherry and blackberry preserves and blackberry jelly, and of utilizing a surplus of fruit existing in certain parts of the state where a satisfactory market was not available for the fresh fruit. The fruit used was obtained from the University farm and other farms in and near the vicinity of Morgantown, the greater part being available within a few hours after picking.

\section{Standardization of Cherry Preserves}

Standard Preserves

The United States Department of Agriculture (15) defines a preserve or jam as "the clean, sound product made by cooking to a suitable consistence, properly prepared fresh fruit, cold pack fruit, canned fruit, or a mixture of two or all of these, with sugar, or with sugar and water. In its preparation not less than 45 pounds of fruit are used to each 55 pounds of sugar. A product in which the fruit is whole or in relatively large pieces is customarily designated a preserve rather than a jam." Preserves may be made according to this standard and still be far from ideal. An ideal cherry preserve should retain the original shape of the cherry and the natural cherry color and flavor, with an agreeable tartness; should contain cherries whole and plump, with tender, unshriveled skins; in a clear syrup, not caramelized, of high concentration of sugar; should have a consistency that is not a jelly; yet should not "run" on a plate.

Attainment of such an ideal preserve from cherries is complicated by 1) lack of pectin to give desirable thickness to the syrup; 2) toughness of skin in some varieties; 3) loss of shape in heating; and 4) lack of sufficient acid in some varieties to yield the necessary tartness. The following factors also are of importance in cooking as affecting the character of the product: amount of sugar, method of adding sugar, temperature of cooking process, variety of cherry, and maturity of cherry. Experimental work was therefore conducted involving the effect of variations of these factors in developing a standard method for cherry preserves.

*Recommendations embodied in the present discussion are outlined in Circular 55 "Blackberry Jelly, Blackberry Jam. and Cherry Preserves," by Hazel Cameron, published by and available upon request from the Agricultural Experiment Station, Morgantown, W. Va. † Mrs. Burns resigned October, 1926. 
The simplest proportion of sugar to cherries employed, complying with the United States Government standard for preserves, was the 50 50 ratio, i. e., equal weights of pitted cherries and sugar. Preliminary work on canned cherries indicated a temperature of $106^{\circ} \mathrm{C}$. as the probable optimum for cherry preserves. Equal weights of washed, pitted cherries and sugar were therefore cooked together to $106^{\circ}$ to serve as a standard for comparison. Varying amounts of sugar were also tried, ranging from 45 percent sugar (a ratio of 45 parts of sugar by weight to each 55 parts of cherries), an amount slightly below the maximum proportion permitted by the government standard, to 60 percent by weight of sugar.

T'able 1 gives the results of this series of trials. It will be noted that 1) the color is noticeably paler with the larger amounts of sugar; 2) the syrup becomes thinner and spreads more freely; 3 ) the preserve is too sweet for the average taste with the larger amounts of sugar unless acid is added; 4) the product is too thin to be ideal, the cherries being distributed through a large proportion of syrup; and 5) the yield increases slightly with the increased amounts of sugar. The lower proportion of sugar was therefore judged to be more satisfactory, and the 50-50 ratio was used as a convenient standard.

\section{Metbod of Adding Sugar}

In the preparation of preserves two general methods are used for the addition of the sugar:

1. The sugar is made into a syrup in which the fruit is cooked.

2. Dry sugar is added to the fruit and cooked to the desired consistency.

The first method is usually regarded as best for retaining the shape of the fruit, particularly for berries (16). Since cherries, having a thicker skin, show a tendency to shrink considerably when introduced into syrups of heavy sugar concentration, a thin syrup was made from one cup sugar and two cups water, boiled one minute, then cooled. In this syrup the washed, pitted cherries were allowed to stand 18 to 24 hours. The juice was then drained off and enough additional sugar added. to make the total weight of sugar equal to the weight of pitted cherries. This was heated to boiling, when the cherries were dropped in and cooked to temperature. Trials were also made with heavy syrups ( 3 cups sugar to 2 cups water) in which the cherries stood 18 to 48 hours. The cherries showed little shrinkage during soaking or cooking, but during cooling, as the syrup penetrated the cherries, they shriveled decidedly. The resulting product also contained an undesirably large proportion of syrup not absorbed by the cherries, and for these two reasons the method was abandoned in favor of the second method.

The effect was tried next of adding the dry sugar in small increments at intervals of 2 to 18 hours and heating to $82^{\circ} \mathrm{C}$. with each addition of sugar. Washed pitted cherries were allowed to stand over night in the refrigerator with one-fourth their weight of sugar. In the morning they were heated again to $82^{\circ}$ with an additional one-fourth weight of sugar, and allowed to stand from 2 to 8 hours, when another 


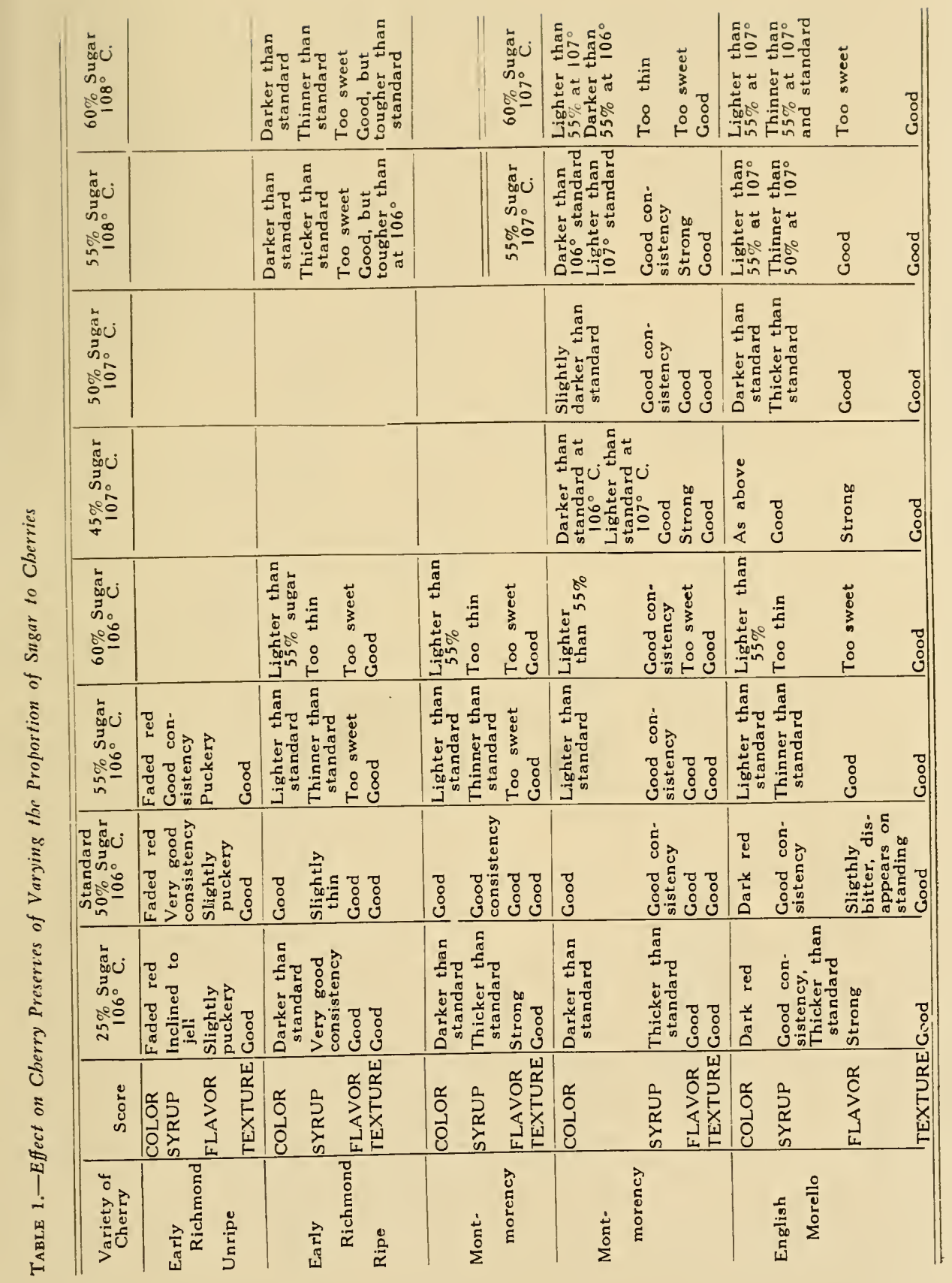


TABIE 2.-Effect of Temperature in Making Cherry Preserves

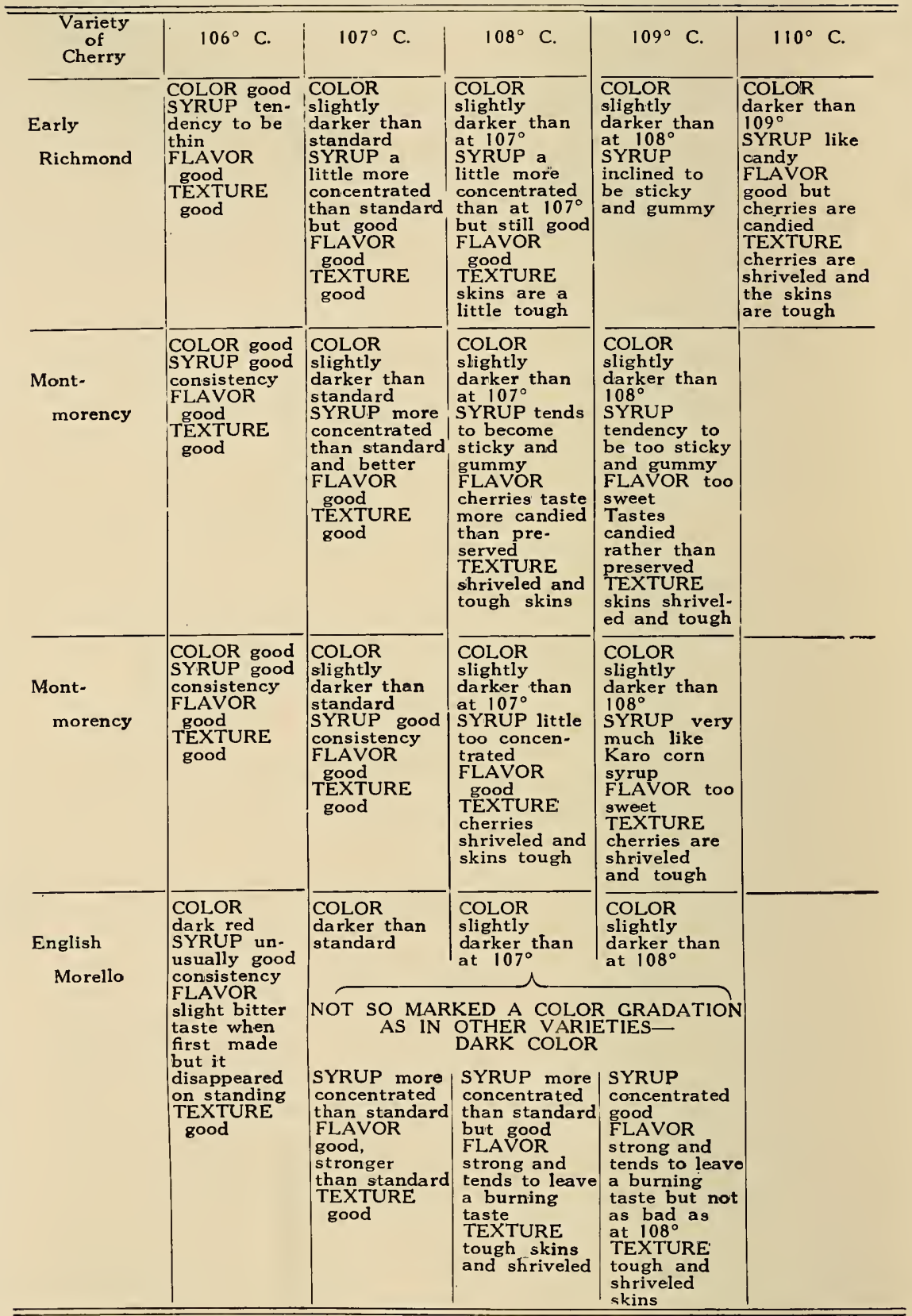


TABLE 2.-Effet of Temperature in Making Cherry Preserves-ConTINUED

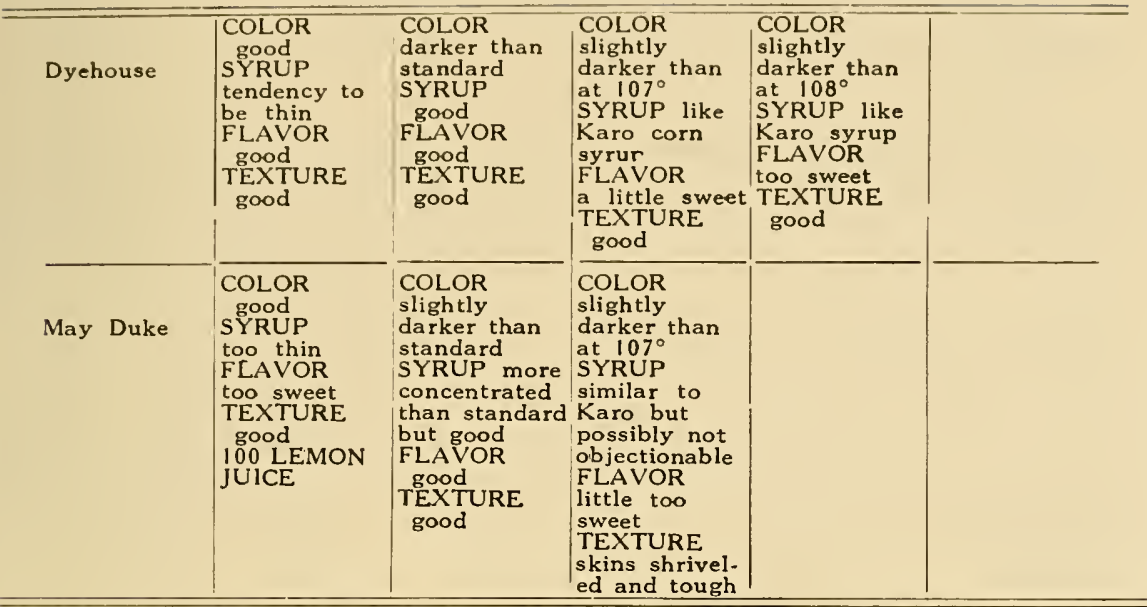

NOTE: To $1000 \mathrm{gm}$. of pitted cherries, $1000 \mathrm{gm}$. of sugar was added and heated to various temperatures. Yield was approximately 2 pts. in each case.

one-fourth portion of sugar was added. Again they were allowed to stand 2 to 8 hours. With final addition of sugar the preserves were heated to $106^{\circ}$ and sealed into jars.

The preserves made by adding sugar at 2 -hour intervals were deemed equally as good in tenderness, consistency, and retention of shape without shriveling, as those involving a longer interval of time.* There was less shriveling of skin and less shrinking of cherries in this method than when the sugar was added in one portion, particularly in the case of sweet cherries. However, since standing extracts more juice, the consistency of the product was a little thin when not altered by the addition of pectin in some form or by discarding part of the juice. From one-half to one cup of syrup from $1000 \mathrm{gms}$. of cherries can be discarded in sealing the preserves, and used as a sauce for ice cream or puddings, or in lemonade. This leaves a preserve with less juice and with very desirable consistency.

Effect of Temperature Variations

The effect on consistency of varying the temperature is shown in Table 2. With the standard method as outlined, equal weights of pitted cherries and sugar were heated to temperatures of from $106^{\circ}$ to $110^{\circ}$ C., at 1-degree intervals. Temperatures below $106^{\circ}$ usually yielded a consistency too thin to be termed a preserve. It was found that increasing the temperature 1) darkens the color of the preserves, 2) increases the thickness of the syrup, and 3) shrivels and toughens the skins of the cherries. Temperature of $106^{\circ}$ to $106.5^{\circ}$ was therefore judged most satisfactory for general use.

Cooking cherry preserves to temperature is subject to considerable inaccuracy since the mixture is not homogeneous; yet it has been the only known improvement over the "inspection" method in the home. The commercial method of cooking a product until its final weight

*All preserves were scored by a committee of three to five judges. 
bears a certain relation to its original weight-known as the "percent of kettle yield" - offered some promise for household use. Therefore, the final end weight of cherry preserves was taken when a temperature of $105^{\circ}$ to $107^{\circ} \mathrm{C}$. was reached.

The average percentage of kettle yield for each variety for the years 1927 and 1928 is given in Table 3, together with the number of tests from which the average is taken. In Table 4 , averages are given for those products only which scored "good", for the years 1927 and 1928 , at temperatures of $105^{\circ}$ to $107^{\circ} \mathrm{C}$., the majority at $106^{\circ}$. It will be seen that for the products rated "good", the average for all varieties is 79 and 81 , respectively, for 1927 and 1928 .

TABLE 3.-Kettle Yield in Percent for All Cherry Preserves at Temperatures of $105^{\circ}$ to $107^{\circ} \mathrm{C}$.

\begin{tabular}{|c|c|c|c|c|}
\hline \multirow{2}{*}{ Variety } & \multicolumn{2}{|r|}{1927} & \multicolumn{2}{|r|}{1928} \\
\hline & Percent & Number of Trials & Percent & Number of Trials \\
\hline $\begin{array}{l}\text { Early Richmond } \\
\text { Montmorency } \\
\text { Dyehouse } \\
\text { May Duke }\end{array}$ & $\begin{array}{l}80.2 \\
76.7 \\
\cdots \cdots . . \\
\cdots \cdots . .\end{array}$ & $\begin{array}{l}10 \\
29 \\
\cdots . . \\
\cdots . .\end{array}$ & $\begin{array}{l}83 \\
83.7 \\
77 \\
76\end{array}$ & $\begin{array}{r}10 \\
28 \\
6 \\
9\end{array}$ \\
\hline Average & 77.5 & & 79.9 & \\
\hline
\end{tabular}

The average percentage for May Duke and Dyehouse cherries was somewhat lower, but the number available was small; the bulk of the cherries used for experimental work in the homes throughout the state being either Early Richmond or Montmorency, particularly the latter. For 1929, therefore, the figure 85 was used as the trial percentage of kettle yield. Cherry preserves were cooked to that figure, and the temperature recorded. Of 30 tests, all scored good, recording a temperature of $105.5^{\circ}$ to $107^{\circ} \mathrm{C}$; 88.8 percent indicating a temperature of between $106^{\circ}$ and $106.5^{\circ}$. For Montmorency cherries at least, therefore, a kettle yield of 83 to 85 percent yields a satisfactory product. The end weight desired is calculated at the beginning by taking 83 or 85 percent of the combined weight of cherries and sugar. Frequent weighings may be necessary to attain the exact point desired but with practice, only two may be necessary, obviating the use of a thermometer and the stirring it necessitates.

Effect of Adding Pectin

Since increasing the thickness of cherry preserves through increase of temperature shrivels the fruit undesirably, the effect was tried of thickening by means of added pectin. Three types of pectin were used: (1) homemade apple pectin, (2) commercial pectin solution, and (3) powdered apple pectin. ${ }^{* \dagger}$

Homemade pectin solution, obtained from apples by the method of Denton, Johnstin, and Yeatman (17), was prepared for experimental work. Analysis of the pectin solution made from apples by this method and of a commercial liquid pectin gave the following percentages for pectic substance: (1)

\footnotetext{
*NUTRL-JEL, supplied by Speas Manufacturing Co., Kansas City, Mo.

The term pectin here is used in the sense defined by the American Chemical Society as "water-soluble methylated pectic substance-obtained by the restricted hydrolysis of the protopectin occurring naturally in plant tissues." Protopectin is the gelatinizable parent substanoe, found in fruits and succulent edible vegetables, which on boiling with water yields pectin-the substance which gives to fruit juices their "jellying" property.
} 
Homemade apple pectin

Commercial apple pectin
Alcobol Precipitate

1.09 percent

3.08 percent
Pectic Acid

0.73 percent

1.56 percent

It is evident therefore that homemade apple-pectin solution was more dilute as regards pectic substances than the commercial and would require a larger amount to produce the same consistence. This is borne out by the findings given below.

Commercial and homemade apple pectin solutions were used in similar manner. Equal weights of washed pitted cherries and sugar (1000 grams of each) were heated quickly to $106^{\circ} \mathrm{C}$. Pectin solution was added in the amounts given in Tables 5 and 6 . The mixture was allowed to boil 1 minute, then to stand 5 minutes before skimming and sealing into jars. Both the commercial and homemade apple pectin solutions were used in amounts of 25,50 , and 100 c.c. per $1000 \mathrm{gm}$. of cherries. In addition, a full bottle of each (200 c. c. or about 1 cup) was used as follows:

One thousand $\mathrm{gm}$. of pitted cherries were simmered in a small amount of water for 10 minutes, when $1470 \mathrm{gm}$. of sugar was added, and the whole quickly brought to the boiling temperature and boiled one minute. The pectin solution was added at this point and allowed to stand 5 minutes with frequent stirring, then skimmed and sealed. Since this product was judged too sweet as well as decidedly too stiff, the former method was substituted.

The yield of preserves in which the larger amount of sugar was used was about 3 pints; with a smaller amount of sugar (equal weights of cherries and sugar), either with or without amounts of pectin varying from 25 to 100 c. c., the yield was 2 pints. In other words, the yield is dependent on the amount of sugar used. Larger amounts of sugar necessitate pectin for thickening. The cherries in this product are suspended in a larger amount of juice, which is economical only if the sugar used is cheaper than the cherries. Since the larger amount of sugar was found too sweet for the average taste, equal weights of cherries and sugar were subsequently used, with the addition of small

TABLE 4.-Kettle Yield in Percent for Cherry Preserves at $105^{\circ}$ to $107^{\circ}$ C., Rated as "Good"

\begin{tabular}{|c|c|c|c|c|c|}
\hline \multirow{2}{*}{ Variety } & \multicolumn{2}{|r|}{1927} & \multicolumn{3}{|c|}{1928} \\
\hline & Percent & Number of Trials & Percent & Number of & Trials \\
\hline $\begin{array}{l}\text { Early Richmond } \\
\text { Montmorency } \\
\text { Dyehouse } \\
\text { May Duke }\end{array}$ & $\begin{array}{l}79 \\
79 \\
\cdots \\
\cdots . .\end{array}$ & $\begin{array}{r}5 \\
2 \\
\cdots . . \\
\cdots . .\end{array}$ & $\begin{array}{l}84 \\
83.9 \\
76.8 \\
77.8\end{array}$ & $\begin{array}{r}7 \\
21 \\
6 \\
5\end{array}$ & \\
\hline Average & 79 & & 811 & & \\
\hline
\end{tabular}

amounts of pectin solution when greater thickness was desired (see Table 5).

In some instances the preserves made with the commercial pectin solution, although at first too stiff, after standing 2 or 3 months became too thin to be classed as preserves. No satisfactory explanation can be given for this phenomenon. The work of Tarr, Myers, and Baker at 
the Delaware Station $(8,12,13)$ suggests that the hydrogen-ion concentration is probably an important factor. Little if any difference could be detected in preserves boiled one minute after the addition of pectin and in those merely allowed to stand 5 minutes. The color of the preserves, however, was considerably darker, and the flavor less natural, when the pectin solution was added at the beginning of the cooking process. The most satisfactory method therefore seems to be to add the pectin just at the end of boiling. Preserves which were allowed to stand in the kettle until cold, with frequent stirring, showed better consistency and greater plumpness, whether with or without added pectin. This standing interval is therefore recommended.

Dry apple pectin when used was mixed thoroughly with an equal amount of sugar, added slowly to a part of the juice of the cherries at boiling point and boiled until dissolved, then added to the cherries and the remainder of the sugar. The whole then was cooked to $106^{\circ}$ as before. The total amount of sugar was kept equal to the weight of pitted cherries. Quantities of dry pectin, from 14 to $20 \mathrm{gm}$. per 1000 gm. of cherries, were used with the results as given in Tables 5 and 6 .

From these results it was concluded that for sour cherries 30 to 40 c.c. of commercial apple pectin solution per $1000 \mathrm{gm}$. of cherries,

TABlE 5.-Effect on Cherry Preserves of Additions of Commercial Pectin Solution

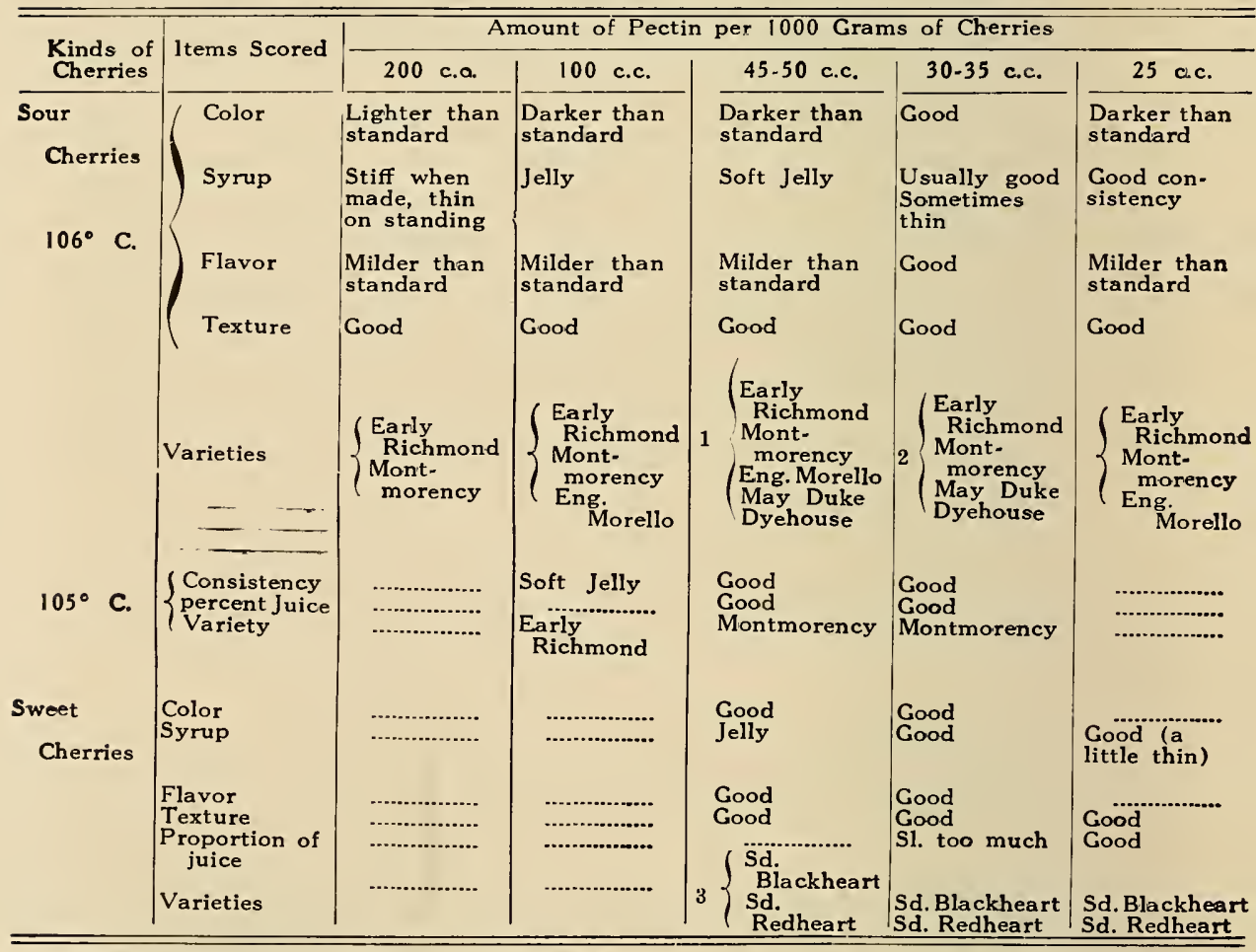

ISlight bitter taste, disappears on standing.

In some cases grew thin on standing.

- Flavor improved by 11 c.c. $4 \%$ citric acid. Flavor less good with 22 c.c. citric acid. 
TABLE 6.-Effect on Cherry Preserves of Additions of Homemade and Dry Apple Pectin

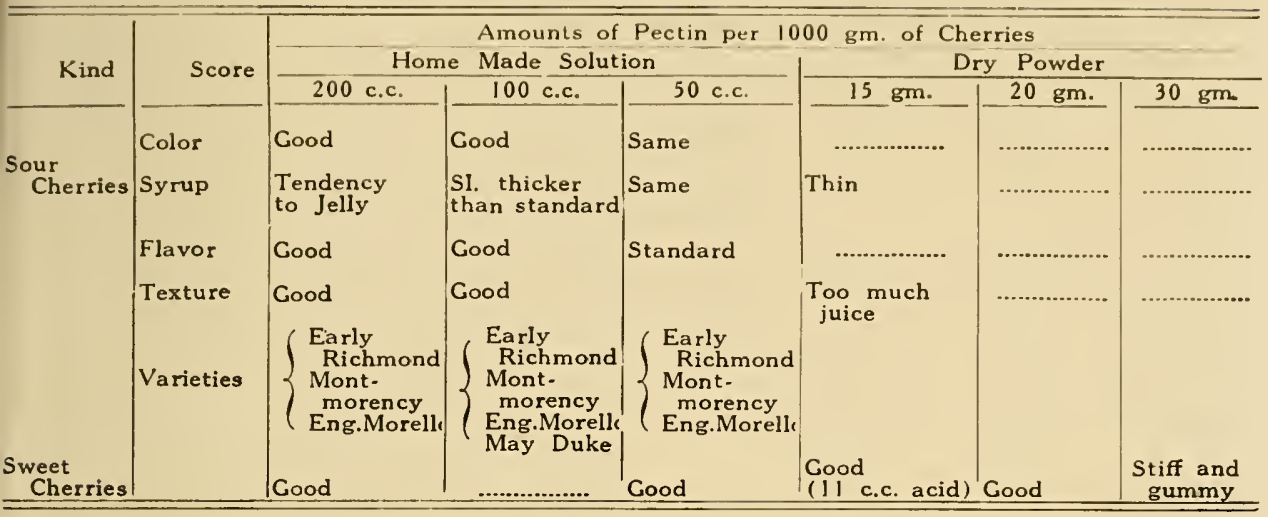

or 100 c.c. of homemade apple-pectin solution, improved the consistency of the preserves without injuring the flavor. For sweet cherries, II c.c. of 4 percent citric acid and 25 to 35 c.c. commercial applepectin solution or 15 to $20 \mathrm{gm}$. of powdered apple pectin, improved the product. These amounts did not noticeably alter the natural cherry flavor of the preserve. Larger amounts gave products too stiff and jelly-like for a preserve. Results were somewhat variable, however, as some of the thickest preserves became thin on standing.

Assuming that the content of alcohol precipitate is a measure of the pectin content and hence of the thickening power of pectin solution, one would expect to require 2.82 times as much of the homemade apple-pectin solution used in this work, as of the commercial product, since the latter gave 3.8 percent alcohol precipitate, as against 1.09 percent for the former (2.82 times as much). Actually this was found true, as 100 c.c. of homemade apple-pectin solution gave approximately the same consistency as 25 to 35 c.c. of the commercial. Homemade solutions would of course vary with the degree of concentration reached in preparation as well as with the variety of apple, storage time, and other factors.

\section{Effect of Variety}

Varieties used included Early Richmond, Montmorency, Dye House, English Morello, Seedling Redhearts, Seedling Blackhearts, and May Duke. Chemical analyses of all except the last three varieties are given in Table 7 . The best preserves were obtained from partially ripe Early Richmonds, from Montmorency, May Duke, and English Morello; in other words, from those varieties richest in pectin and acid. The English Morello was especially desirable, the pectin and acid content of its juice being sufficiently high to make a real jelly when sugar was combined with it in the proportion of one-half measure of sugar to one measure of juice. The strong, slightly bitter taste at first noticeable in these preserves disappears entirely on standing. A dark, rich red preserve of desirable consistency and flavor results. 
TABLE 7.-Chemical Analyses of Cherries

\begin{tabular}{|c|c|c|c|c|c|c|c|c|}
\hline $\begin{array}{l}\text { Variety of } \\
\text { Cherry }\end{array}$ & $\begin{array}{c}\text { Stage } \\
\text { of } \\
\text { Ripening }\end{array}$ & $\begin{array}{l}\text { Alcohol } \\
\text { Pre- } \\
\text { cipitate }\end{array}$ & $\begin{array}{l}\text { Pectic } \\
\text { Acid }\end{array}$ & $\begin{array}{l}\text { Total } \\
\text { Solids }\end{array}$ & $\begin{array}{l}\text { Total } \\
\text { Ash }\end{array}$ & $\begin{array}{l}\text { Invert } \\
\text { Sugar }\end{array}$ & $\begin{array}{l}\text { Balling } \\
60^{\circ} \mathrm{F} .\end{array}$ & $\begin{array}{l}\text { Acidity -c.c. } \\
\text { N / } 10 \text { Alk. to } \\
\text { neutralize } \\
100 \mathrm{gm} .\end{array}$ \\
\hline $\begin{array}{l}\text { Early } \\
\text { Richmond }\end{array}$ & unripe & $\begin{array}{r}\text { percent } \\
.1918 \\
\end{array}$ & $\begin{array}{r}\text { percent } \\
.1184\end{array}$ & $\begin{array}{r}\text { percent } \\
10.14\end{array}$ & $\begin{array}{r}\text { percent } \\
.595\end{array}$ & $\begin{array}{l}\text { percent } \\
10.27\end{array}$ & $\begin{array}{l}\text { percent } \\
15.98\end{array}$ & 234.6 \\
\hline $\begin{array}{l}\text { Early } \\
\text { Richmond }\end{array}$ & ripe & .238 & .1459 & 27.18 & .757 & 10.39 & 20.13 & 230.7 \\
\hline $\begin{array}{l}\text { Mont- } \\
\text { morency }\end{array}$ & unripe & .1676 & .0809 & 35.8 & .4002 & 7.19 & 14.97 & 194.6 \\
\hline $\begin{array}{l}\text { Mont- } \\
\text { morency }\end{array}$ & ripe & .280 & .145 & ......... & .483 & 10.17 & 17.9 & 271.2 \\
\hline $\begin{array}{l}\text { English } \\
\text { Morello }\end{array}$ & unripe & .380 & .235 & 46.4 & .498 & 8.17 & 16.72 & 546.6 \\
\hline $\begin{array}{l}\text { English } \\
\text { Morello }\end{array}$ & ripe & .257 & .169 & .......... & .471 & 9.09 & 14.04 & 364.0 \\
\hline Dyehouse & overripe & .197 & .565 & 23.25 & .634 & 10.29 & 14.58 & 189.3 \\
\hline $\begin{array}{l}\text { Sweet } \\
\text { Cherries }\end{array}$ & rips & .271 & .169 & 28.98 & .856 & 15.09 & $\ldots$ & 408.0 \\
\hline
\end{tabular}

Seedling Blackhearts and Redhearts show an undesirably tough skin, not improved by preserving, and require the addition of acid to bring out the best flavor and texture. Blackhearts, in spite of tough skin, made a well-liked preserve, however, when prepared according to the method recommended with addition of 11 c.c. of 4 percent citric acid at the end of cooking. Some of the early sour cherries have a large seed and thin soft pulp which will not yield whole, plump fruit for preserving. These are likely to be broken up in cooking and are therefore better used for canning or for combining, whole or ground, with other fruits for marmalade.

\section{Effect of Maturity}

The effect of maturity of fruit for cherry preserves was tried on two varieties, Early Richmond and English Morello, for which unripe cherries were available. According to the theory of its formation, pectin should be more abundant in unripe than in ripe fruit. The alcohol test for pectin (equal measures of alcohol and cooked fruit juice) and chemical analysis both attest this theory. Preserves therefore were made using $25,50,75$, and 100 percent partly ripe cherries of the varieties mentioned. For early Richmond the color was found to grow lighter with each successive 25 percent addition of unripe cherries. With 100 percent of partly ripe cherries the juice of the preserves was colored only a light faded red. For English Morello the opposite was true, the color deepening with each successive 25 percent addition of unripe fruit (Table 8 ). The concentration of the juice increased with the unripe fruit, but the skins showed a tendency toward toughness. Therefore, while slight improvement in consistency was obtained by the use of 25 to 50 percent of unripe fruit, the toughness of skin and the slightly bitter taste rendered such addition undesirable. In general, variations in ripeness made greater differences in preserves than did differences in varieties among sour cherries. 
Subsequent work on Early Richmond cherries has shown that the commercial practice of soaking the cherries as soon as picked, for from 4 to 8 hours or overnight in cold water before pitting, helps to plump them and preserve their shape.

Conclusions
Soaking cherries in cold water for several hours before pitting helped to plump them and retain their shape.

Equal weights of sugar and cherries yielded the most desirable cherry preserves from the standpoint of sweetness and consistency and still complied with the government requirement.

The addition to the cherries of one-fourth to one-third of the dry sugar at a time, heating just to boiling, and allowing to stand 2 to 18 hours between additions, helped to retain the shape of the cherries with a minimum of shriveling.

Final temperature of $106-10612^{\circ} \mathrm{C}$. (at approximately $900 \mathrm{ft}$. elevation) gave the best product as regards shrinkage, shriveling, toughness, and texture. Cooking until the final weight was 83 to 85 percent of the total weight at the beginning ( $83-85 \%$ kettle yield) gave more uniform results than cooking to temperature.

The addition of 30 to 40 c.c. of commercial pectin solution or 100 c.c. of homemade apple pectin per $1000 \mathrm{gm}$. cherries gave a desirable consistency for cherry preserves without producing a jelly.

The addition of small amounts of acid is an improvement to sweet cherries used for preserves ( 10 c.c. of $4 \%$ citric acid per $1000 \mathrm{gm}$.).

Variety is an important factor in making good cherry preserves. The best results were obtained from those varieties having the larger proportions of pectin and acid (Montmorency, May Duke, English Morello) and relatively small seed.

The addition of some partly ripe cherries improved the consistency somewhat; but less than 25 percent should be used in order to avoid undue toughness of skin and bitterness of flavor.

TABLe 8.-Effect of Maturity on Cherry Preserves

\begin{tabular}{|c|c|c|c|c|c|}
\hline $\begin{array}{c}\text { Variety } \\
\text { of } \\
\text { Cherry }\end{array}$ & $\begin{array}{c}25 \% \text { Unripe } \\
75 \% \text { Ripe } \\
\end{array}$ & $\begin{array}{c}50 \% \text { Unripe } \\
50 \% \text { Ripe }\end{array}$ & $\begin{array}{l}75 \% \text { Unripe } \\
25 \% \text { Ripe }\end{array}$ & $100 \%$ Unripe & $\begin{array}{c}100 \% \text { Ripe } \\
\text { or } \\
\text { Standard }\end{array}$ \\
\hline $\begin{array}{l}\text { Early } \\
\text { Richmond }\end{array}$ & $\begin{array}{l}\text { COLOR light red } \\
\text { SYRUP less con- } \\
\text { centrated than } \\
\text { standard } \\
\text { FLAVOR mild } \\
\text { TEXTURE } \\
\text { cherries a } \\
\text { little tough }\end{array}$ & $\begin{array}{l}\text { COLOR lighter } \\
\text { than } 25 \% \\
\text { unripe } \\
\text { SYRUP consid- } \\
\text { erably more } \\
\text { concentrated } \\
\text { than } 25 \% \text { and } \\
\text { more than } \\
\text { standard } \\
\text { FLAVOR good } \\
\text { TEXTURE good }\end{array}$ & $\begin{array}{l}\text { COLOR lighter } \\
\text { than } 50 \% \\
\text { SYRUP more } \\
\text { concentrated } \\
\text { than standard } \\
\text { FLAVOR good, } \\
\text { a little } \\
\text { puckery } \\
\text { TEXTURE skins } \\
\text { a little tough }\end{array}$ & $\begin{array}{l}\text { COLOR faded } \\
\text { red } \\
\text { SYRUP very } \\
\text { good con- } \\
\text { sistency } \\
\text { FLAVOR } \\
\text { slightly } \\
\text { puckery } \\
\text { TEXTURE good }\end{array}$ & $\begin{array}{l}\text { COLOR good } \\
\text { SYRUP tendency } \\
\text { to be thin } \\
\text { FLAVOR good } \\
\text { TEXTURE good }\end{array}$ \\
\hline $\begin{array}{l}\text { English } \\
\text { Morello }\end{array}$ & $\begin{array}{l}\text { COLOR possibly } \\
\text { darker than } \\
\text { standard } \\
\text { SYRUP slightly } \\
\text { more concen- } \\
\text { trated than } \\
\text { standard } \\
\text { FLAVOR strong } \\
\text { TEXTURE skins } \\
\text { are a little } \\
\text { tougher than } \\
\text { standard }\end{array}$ & $\begin{array}{l}\text { COLOR darker } \\
\text { than standard } \\
\text { SYRUP inclined } \\
\text { to jell } \\
\text { FLAVOR strong } \\
\text { TEXTURE skins } \\
\text { are little } \\
\text { tougher than } \\
\text { standard }\end{array}$ & $\begin{array}{l}\text { COLOR darker } \\
\text { than standard } \\
\text { SYRUP a little } \\
\text { thin } \\
\text { FLAVOR strong } \\
\text { TEXTURE skins } \\
\text { are tougher } \\
\text { than standard }\end{array}$ & $\begin{array}{l}\text { COLOR same } \\
\text { as standard } \\
\text { rip } \\
\text { SYRUP a little } \\
\text { thin } \\
\text { FLAVOR bitter } \\
\text { TEXTURE tough }\end{array}$ & $\begin{array}{l}\text { COLOR dark } \\
\text { red } \\
\text { SYRUP un- } \\
\text { usually good } \\
\text { consistency } \\
\text { FLAVOR slight } \\
\text { bitter taste } \\
\text { when first } \\
\text { made but it } \\
\text { disappeared } \\
\text { on standing } \\
\text { TEXTURE good }\end{array}$ \\
\hline
\end{tabular}




\section{BLACKBERRY PRESERVES}

The definition of blackberry preserves corresponds to that of cherry preserves, the United States standard applying to both. The ideal also resembles that of cherries; i. e., whole unshriveled fruit in a juice of such consistency that it will not "run" on a plate, nor classify as a jelly.

Since blackberries are less sour than sour cherries, preserves using more than equal weights of sugar were found too sweet. By using a method similar to that for cherries, blackberry preserves were made by heating together, without water, equal weights of washed blackberries and sugar. Temperatures of $104^{\circ}, 105^{\circ}, 106^{\circ}$, and $107^{\circ} \mathrm{C}$. were tried, with the results shown in Table 9. Judging committees agreed that in the majority of cases a temperature of 105 to $106^{\circ} \mathrm{C}$. gave the product most satisfactory in consistency and texture.

Analysis shows that unripe berries contain more pectin than ripe berries. Since consistency depends very largely on pectin content, the effect therefore was tried of using various proportions of unripe berries. Results from the trials with from 25 to 50 percent unripe berries showed no improvement in product. However, the use of 10 percent unripe berries is recommended for preserves to offset any possible overripeness.

TABLE 9.-Effect of Temperature in Making Blackberry Preserves

\begin{tabular}{|c|c|c|c|c|c|}
\hline \multirow{2}{*}{ Lot } & \multirow{2}{*}{ Items Scored } & \multicolumn{4}{|c|}{ Temperature } \\
\hline & & $104^{\circ} \mathrm{C}$ & $105^{\circ} \mathrm{C}$. & $106^{\circ} \mathrm{C}$. & $107^{\circ} \mathrm{C}$. \\
\hline \multirow{2}{*}{ I } & $\begin{array}{l}\text { Color } \\
\text { Syrup }\end{array}$ & $\begin{array}{l}\text { good } \\
\text { too thin }\end{array}$ & $\begin{array}{l}\text { good } \\
\text { good }\end{array}$ & good & \\
\hline & $\begin{array}{l}\text { Flavor } \\
\text { Texture }\end{array}$ & $\begin{array}{l}\text { little tart } \\
\text { good }\end{array}$ & $\begin{array}{l}\text { good } \\
\text { good }\end{array}$ & very good & \\
\hline II & $\begin{array}{l}\text { Color } \\
\text { Syrup } \\
\text { Flavor } \\
\text { Texture }\end{array}$ & $\begin{array}{l}\text { good } \\
\text { good } \\
\text { good } \\
\text { good }\end{array}$ & $\begin{array}{l}\text { good } \\
\text { good } \\
\text { good } \\
\text { good }\end{array}$ & $\begin{array}{l}\text { good } \\
\text { too thick } \\
\text { good } \\
\text { good }\end{array}$ & $\begin{array}{l}\text { good } \\
\text { too thick } \\
\text { good } \\
\text { berries } \\
\text { little tough }\end{array}$ \\
\hline III & $\begin{array}{l}\text { Color } \\
\text { Syrup } \\
\text { Flavor } \\
\text { Texture }\end{array}$ & $\begin{array}{l}\text { good } \\
\text { fair } \\
\text { too tart } \\
\text { good }\end{array}$ & $\begin{array}{l}\text { good } \\
\text { good } \\
\text { tart } \\
\text { good }\end{array}$ & $\begin{array}{l}\text { good } \\
\text { good } \\
\text { tart } \\
\text { good }\end{array}$ & $\begin{array}{l}\text { good } \\
\text { too thick } \\
\text { tart } \\
\text { berries } \\
\text { tough }\end{array}$ \\
\hline IV & $\begin{array}{l}\text { Color } \\
\text { Syrup } \\
\text { Flavor }\end{array}$ & $\begin{array}{l}\text { good } \\
\text { too thin } \\
\text { tart }\end{array}$ & $\begin{array}{l}\text { good } \\
\text { good } \\
\text { slightly }\end{array}$ & $\begin{array}{l}\text { good } \\
\text { good } \\
\text { good }\end{array}$ & $\begin{array}{l}\text { good } \\
\text { good } \\
\text { good }\end{array}$ \\
\hline & Texture & good & good & good & $\begin{array}{r}\text { berries } \\
\text { tough }\end{array}$ \\
\hline
\end{tabular}

Standard for Jelly

\section{BLACKBERRY JELLY}

The United States Government prescribes for jelly the following standard: "Jelly, fruit jelly, is the clean sound semi-solid gelatinous product made by concentrating to a suitable consistence, the strained juice or the strained water extract from fresh fruit, from cold pack fruit, from canned fruit, or from a mixture of two or all of these with sugar (sucrose)" (15). Such a standard permits considerable latitude in judging "suitable consistence." An ideal as well as a standard becomes necessary. Goldthwaite (6) describes the ideal fruit jelly as 
"the beautifully colored, transparent, palatable product obtained by so treating fruit juice that the resulting mass will quiver and not flow when removed from its mold; a product with texture so tender that it cuts easily with a spoon and yet so firm that the angles thus produced retain their shape; a clear product that is neither syrupy, gummy, sticky or tough; neither is it brittle; yet it will break, and does this with a distinct, beautiful cleavage which leaves sparkling, characteristic faces. This is that delicious, appetizing substance-a good jelly."

Essential Ingredients for Jelly

To assure such a product, 4 ingredients usually are regarded as necessary-water, acid, pectin, and sugar.

Water. Water is furnished by the blackberries themselves, which contain 80 percent of water, and also by the water used in extracting the juice for jelly. Too large a proportion of water of course results in a solution too dilute for satisfactory jelly; but this is usually described as "too poor in pectin" rather than as "too rich in watc, r".

Acid. Jelly can be made from pectin solutions without acid, if certain salts are present; but McNair (9) suggests that this action is really due to the hydrogen-ion present in the salt or on hydrolysis; and Myers and Baker (8) emphasize the buffer effect or salts on the weak acids of fruit jellies.

Nelson (10) finds in blackberries isocitric, l-malic, and traces of oxalic, succinic, and citric acids. Figures for the percentage of acid necessary for jelly formation are conflicting. Goldthwaite (5) reports good jelly from fruits varying from neutral to 0.669 percent acidity (expressed as sulphuric acid); Cruess and McNair (3) give the optimum acidity as 0.35 to 1.05 percent (as sulphuric); Singh (11), from 0.035 to 2.835 percent (as sulphuric), depending on the proportion of sugar used, a factor which he regards very important.

Less malic than citric acid seems to be required, and Tarr (12) reports tartaric as the most efficient of the common fruit acids. His work. also shows that the total acidity of fruit juice used for jelly cannot be correlated with the jellying power, but that the available acid: i. e., the hydrogen-ion concentration, bears a close relation to jellying power. This explains the apparent discrepancy in the figures given above for acidity necessary for jellying, and gives an excellent means of controlling the jellying of fruit juices. For the pectin used in the experimental work of Tarr, $\mathrm{pH} 3.46$ was the minimum hydrogenion concentration for jelly formation, and $\mathrm{pH} 2.9$ to 3.0 , the maximum.

Figures are not available for hydrogen-ion concentration of the blackberry juice used in the earlier experiments at this Station; but figures were determined in the later work by means of a Youden Quinhydrone Hydrogen electrode apparatus. In all these cases they

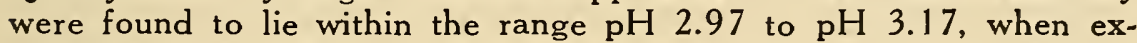
tractions were made with distilled water, as outlined under "Method of Procedure". These fruit juices are of course not pure pectin solutions as used at the Delaware Station, but jelly stock as used in the ordinary preparation of jelly. To some of the juice having a $\mathrm{pH}$ of 3.066 , solid tartaric acid was added in varying amounts, yielding juice 
of $\mathrm{pH} 2.715,2.885$, and 2.29. The results of the scores on jellies made from these juices are shown in Table 10 . These results show that with juices as acid as $\mathrm{pH} 2.7$ the majority of jellies made (with different proportions of sugar) were fair or better; below this $\mathrm{pH}$ few of the jellies were even fair, while at $\mathrm{pH} 3.066$ all scored above 80 , - the majority above 90 .

Pectin. Pectin is used here in the same sense as in the section on cherry preserves (page 7). From the work of the Delaware Station, the actual amount of pectin, provided it is present at all, seems much less important than the hydrogen-ion concentration, which makes the pectin available for jellying (12). In Table 11 are given analyses of typical lots of blackberries for pectin and pectic acid. The alcohol precipitate test for pectin was checked with these analyses and with the determinations of $\mathrm{pH}$ to determine its value to the housewife when other tests are not available. For this test, one teaspoonful of the cooked, cooled fruit juice was put into a shallow cup; to it was added an equal volume of alcohol (denatured alcohol may be used). The two were mixed by gently tipping the cup. If a thick gelatinous mass formed within a few minutes with little or no liquid left, the pectin test was described as "very good"; if slightly more liquid was left, as "good"; if only a few gelatinous lumps formed, as "fair"; and if only a few small flakes, as "poor". This test was used to determine roughly the amount of sugar to be added also and is discussed under sugar.

Sugar. Jelly can be made without added sugar, but the result is sour and tough, is not economical because it requires a large amount of fruit juice, and is neither a standard nor an ideal jelly. The real function of sugar in jellying is not well understood, its use having been largely to improve flavor and texture. McNair (9) suggests that dehydration is one possible function, since the point of jelly formation comes when the solution is approximately saturated with sugar. A second function may be that of increasing viscosity-also a factor of importance in determining the jellying point. It has long been known that too little sugar gives a sour, tough jelly, while too much

$\mathrm{T}_{\mathrm{ABLE}}$ 10.-Results on Jellies of Increasing the Hydrogcn-Ion Concentration

\begin{tabular}{|c|c|c|c|c|c|}
\hline Lot & $\mathrm{pH}$ & Pectin Test & Number & Scoring ___ _ & Remarks \\
\hline & & & Above 80 & Above 90 & \\
\hline $\begin{array}{l}28 \mathrm{~V}-\mathrm{VI} \\
1 \text { and } 2\end{array}$ & 3.066 & Good & All & Majority & \\
\hline 3 & 3.066 & Good & Majority & Good proportion & \\
\hline 4 & 2.715 & Good & $\begin{array}{l}\text { Majority } \\
17 \text { out of } 30\end{array}$ & $\begin{array}{c}7 \text { out of } 30 \\
\text { Scored } 70\end{array}$ & $\begin{array}{l}6 \text { out of } 30 \\
\text { to } 80\end{array}$ \\
\hline 5 & 2.885 & Good & Majority & 13 Majority 20 & $\begin{array}{l}\text { Rest sour, } \\
\text { and thin } \\
\text { but fairly } \\
\text { good jelly } \\
\text { texture }\end{array}$ \\
\hline 7 & 2.29 & Good & 8 out of 31 & 3 out of 31 & $\begin{array}{c}\text { Majority } \\
\text { below } 80 \text {, } \\
\text { most of } \\
\text { them be- } \\
\text { low } 70\end{array}$ \\
\hline
\end{tabular}


TABLE 11.-Composition of Blackberries Used

\begin{tabular}{c|c|c|c|c}
\hline \multirow{2}{*}{ Sample } & $\begin{array}{c}\text { Percent } \\
\text { Water }\end{array}$ & $\begin{array}{c}\text { Percent } \\
\text { Pectin }\end{array}$ & $\begin{array}{c}\text { Percent } \\
\text { Pectic Acid }\end{array}$ & Sugar \\
\cline { 5 - 6 } & 83.64 & 0.501 & 0.307 & 5.46 \\
2 & 87.63 & 0.631 & 0.259 & 6.18 \\
3 & 69.24 & 0.570 & 0.312 & 7.55 \\
4 & 83.68 & 0.586 & 0.328 & 6.10 \\
$* 5$ & 69.15 & 0.840 & 0.450 & 1.93 \\
\hline
\end{tabular}

* Unripe Berries

sugar yields a product too sweet to the taste and too soft to form a true jelly. 'The exact amount to be used has been rather roughly approximated.

The present work was concerned primarily with the development of a practical method for blackberry jelly as a means of utilizing surplus fruit rather than with theoretical considerations in jellying; hence it deals only with the determination of the optimum proportion of sugar to be used under given conditions; and with the selection of a satisfactory end point and the method for its attainment.

\section{Method of Procedure}

Extraction

In the juice-extraction process the berries were washed in a spray of water under the faucet, drained, heated to boiling in a covered kettle, then mashed with a wire masher, and simmered, covered, for 10 minutes (or until soft). They were then drained overnight through two thicknesses of cheesecloth, without pressure. The pulp was returned to the kettle with an equal weight of water, simmered for 10 minutes, and drained again through cheesecloth. A third extraction was made in the same manner, the juice from the several extractions being kept separate. Jelly was made from Extraction I, II, and III separately; from I, II, and III combined; from I to II combined; and from II and III combined.

The yield obtained from the various combinations is shown in Figure 1, and, likewise, the consistency of the jellies. It is evident that a second extraction materially increases the yield of jelly from a given amount of fruit and is well worth while from an economic standpoint if the fruit contains abundant pectin. A third extraction increases the yield to a smaller extent and is perhaps not worth while except for fruit very rich in pectin. All extractions yielded good jelly with the proper amount of sugar. For general purposes, combination of Extractions I and II is quite satisfactory; the second extraction yielded a larger amount of juice than did squeezing the bag after the first extraction, - a procedure which is likely to produce cloudy juice.

For most of the experimental work on blackberry jelly at this Station, large amounts of berries were used. Two extractions were made as outlined above, using distilled water. All of the juice was combined, and aliquots of this taken for the individual tests, thus yielding juice of constant composition. The juice was kept in an electric refrigerator at a temperature of $40^{\circ} \mathrm{F}$. or below. Since in two weeks time the $\mathrm{pH}$ of the juice, originally 3.066, changed to only 3.13 , the juice used for jelly-making, which was kept a much shorter time, was deemed of sufficiently constant composition to show the effects of varying the proportion of sugar and end point. 
On some of the extractions, viscosity was determined by an Oswald viscosimeter to determine if time of flow was sufficiently uniform for the development of a simple test of this nature for jellying power. As expected, difficulties were encountered, since the gases contained in the juice produced bubbles which seriously interfered with the flow, while heating to remove these gases increased the concentration. Wide variations were noted. Thus the viscosity of the filtered juice from one lot of berries was 9.959; on standing, stoppered, in the icebox, 10.909 (even when brought to the same temperature for testing); while on filtered juice from another lot in which the berries had been ground it was found to be 27.085. With such wide variations in a standard method of procedure, no information of value could be expected from a simplified test using much cruder equipment. This work therefore was discarded. At the same time it was noted that if berries were picked when some of them still showed red color, the $\mathrm{pH}$ was in all cases within the range for jellying given by Tarr (12) and yielded good jellies with the proper amount of sugar. For practical use, therefore, the precaution only of picking the berries at this stage need be observed to control the acidity with sufficient accuracy for satisfactory jelly.

Procedure

For most of the work, 300 c.c. portions of juice were used, weighing 306 ( 305 to 307 ) gm. This juice was heated to boiling in small aluminum saucepans of uniform size and shape. The weighed amount of sugar was added. Heating was done on a gas hotplate, the pressure being controlled by a water manometer. Boiling to the desired point was carried on as rapidly as possible without boiling over. Temperatures were read on an armored Centigrade thermometer, reading to 0.1 degree, immersed in the jelly to a depth covering the bulb well. Final readings were taken just before the jelly was removed from the fire. Weight of hot saucepan and jelly was taken on a small platform balance. The jelly was poured at once into hot sterile glasses and sealed the next day with melted paraffin. Some weeks later the jellies were opened, tested by means of a jelly strength tester modelled after that described by Tarr (14), and scored by from 3 to 5 judges, using the following score sheet:

\begin{tabular}{ccc}
\multicolumn{2}{c}{ Jelly Score Card No. 1} & 20 points \\
APPEARANCE & 5 & \\
Transparency & 5 & \\
Color & 5 & \\
Shape & 5 & 35 points \\
Glistening & 10 & \\
TEXTURE & 10 & \\
Tenderness & 10 & 30 points \\
Quivering & 5 & \\
Consistency & 10 & \\
Holding angles & 10 & 15 points \\
FLAVOR Naturalness & 10 &
\end{tabular}




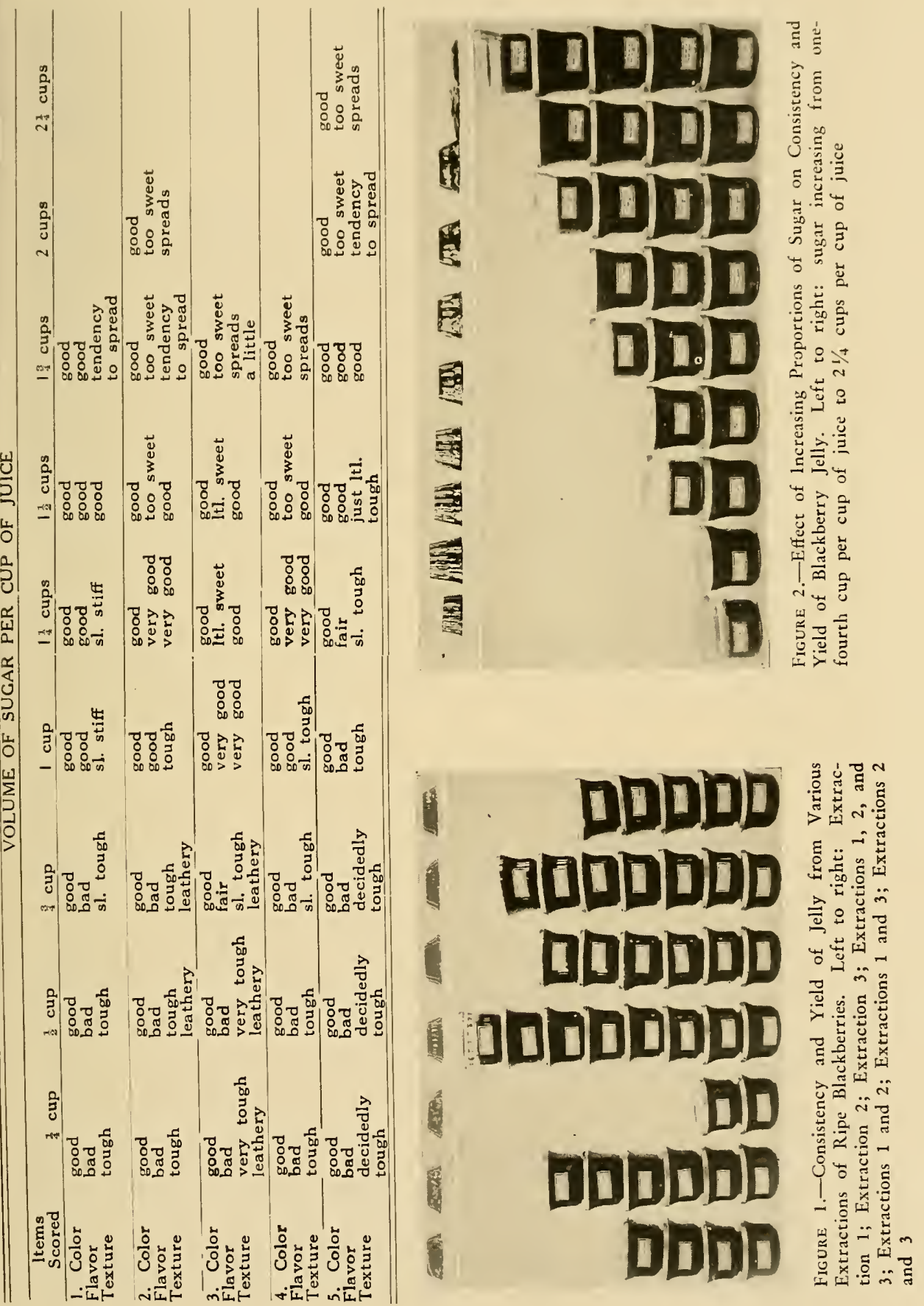


With this amount of juice, little difference was found either in the jellies themselves or in the length of time required to form a jelly, whether sugar was added to the cold juice, or after it reached the boiling point. Only three cases of crystallization occurred (4). No record was kept of losses in skimming from the two methods, Goldthwaite reporting greater losses for jellies in which the sugar was added to the cold juice.

Effect of Varying the Proportion of Sugar

In the preliminary experiments with increasing amounts of sugar, two cups of blackberry juice was used for each test. Increasing amounts of sugar were added to different portions, beginning with one-half cup and increasing the amount by $1 / 2$-cup portions up to $41 / 2$ cups, thus giving proportions (by volume) of sugar to juice of $1 / 4: 1$, $1 / 2: 1,3 / 4: 1,1: 1,1 \frac{1}{4}: 1,1 \frac{1}{2}: 1,13 / 4: 1,2: 1,21 / 4: 1$. The effect on yield and consistency of jelly of increasing the amount of sugar is shown in Figure 2, and the effect on color, flavor, and texture in Table 12. It will be noted that jellies made with the smallest amounts of sugar had a texture very firm and tough, as well as an undesirably sour taste, while those made with the largest amounts of sugar were too soft to hold their shape and had an undesirably sweet taste, thus bearing out the findings for other fruit jellies (7). Between these two extremes, however, was a wide range wherein both texture and flavor were satisfactory.

TABLE 13-Effect on Score of Jelly of Increasing Amonnts of Sugar

\begin{tabular}{ccc}
\hline $\begin{array}{c}\text { Proportion of Sugar to Juice } \\
\text { By Volume }\end{array}$ & By Weight & Average Score* \\
\hline $0.6: 1$ & $2: 1$ & 84.5 \\
$0.9: 1$ & 1 & 87.7 \\
$1.25: 1$ & $1: 1$ & 91.3 \\
$1.5: 1$ & $1 \frac{1}{3}: 1$ & 92.2 \\
$1.6: 1$ & $1 \frac{1}{3}: 1$ & 96.2 \\
$1.8: 1$ & $1 \frac{1}{2}: 1$ & 88.0 \\
\hline
\end{tabular}

* Only those products are included which formed a true jelly.

In later experiments $11 / 2$ cups or $306 \mathrm{gm}$. of juice was used. Sugar was added by weight as more accurate than volumetric measure. In general, the proportion by volume of sugar to juice was approximately one-fourth more than the proportion by weight.

For blackberry juice a larger proportion of sugar to juice can be used advantageously than is usually recommended for other fruit juices. Thus blackberry jellies made with $1 \frac{1}{2}$ to 2 cups of sugar to each cup of juice were good, and those made with $1 \frac{1}{4}$ to $1 \frac{1 / 3}{3}$ cups of sugar per cup of juice were found optimum, whereas for most fruit juices not over one cup of sugar per cup of juice is recommended.

The alcohol test for pectin given above showed some correlation with the amount of sugar that could be added to yield a firm jelly. Thus if this test was "very good" as defined above, good jelly was obtained with $11 / 4$ to $1 \frac{1 / 2}{2}$ volumes of sugar to each volume of juice, and jellies made with less sugar had a much less desirable texture. If the alcohol test was "good", good jelly was obtained with 1 to $11 / 4$ volumes of sugar per volume of juice. With a "fair" test only $3 / 4$ volume of sugar per volume of juice could be used; if "poor", only $1 / 2$ volume. 
Table 13 illustrates how the quality of the jelly, as expressed by the score in percent, improved with increasing amounts of sugar up to a certain point, then declined with further addition of sugar. The figures given are for jellies made from juice at $\mathrm{pH} 3.066$ under identical conditions. They represent the average of from 6 to 12 scores in every case.

Determining when Jelly is Finished

Jelly' Test. Three methods were tried for determining when the jellies were finished: 1) the "jellying point" of the household; 2) temperature; and 3) weight of final product. Jelly has long been tested in the household by the first method by dripping it from a spoon and observing the drops. If they "set" into solid drops of jelly along the edge of the spoon instead of running off as a liquid, the jelly is regarded as finished. A silver spoon was found superior to a wooden spoon for this test. With juice of proper $\mathrm{pH}$ it was surprising how uniformly this test indicated a jelly which later scored well. The temperature at which this test appeared varied with the amount of sugar used as well as with individual observation, but in all cases it fell between $101^{\circ}$ and $103^{\circ} \mathrm{C}$.

Temperature. Temperatures of from $101^{\circ}$ to $107^{\circ} \mathrm{C}$. were tried, readings being taken as described under "Procedure". Above $105^{\circ}$ jellies were strong, tough, and stringy. Between $101^{\circ}$ and $105^{\circ}$ the majority were good. Jellies containing less than one part of sugar by weight to one part of juice did not form a true jelly at $101^{\circ}$. These same jellies at temperatures above $102^{\circ}$ to $103^{\circ}$ were tough and strong. The larger the amount of sugar, up to $11 / 2$ parts by weight, the lower the temperature at which jelly formed. Larger amounts of sugar of course yielded a soft jelly, which on further cooking merely became waxy from concentration of the syrup. With proportions of sugar of $1: 1$ and $11 / 4: 1$ (by weight), temperatures between $101^{\circ}$ and $105^{\circ}$

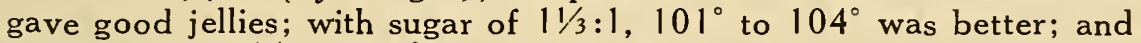
with sugar of $1 \frac{1}{2}: 1,102^{\circ}$ gave the best product.

Temperature readings are not difficult to take with a fair degree of accuracy, especially with a Centigrade thermometer reading to 0.1 degree; and thermometers are used by many housewives. Thermometers are an improvement over the "jelly test," since they eliminate the personal factor; but they may be complicated by differences in elevation and, consequently, in boiling point, - a factor often overlooked. The temperatures given are for 900 feet elevation, $102^{\circ}$ to $103^{\circ} \mathrm{C}$. or $216^{\circ}$ to $217^{\circ} \mathrm{F}$. giving the best results. Deducting one-half degree $\mathrm{C}$. or one degree $\mathrm{F}$. for each 500 feet elevation above sea level provides a sufficiently accurate correction for blackberry jelly, particularly since on standing the jelly becomes slightly more firm in either case.

Cooking to Weight. To avoid the inaccuracies due to elevation and other barometric changes, and to provide a method for those housewives who do not have thermometers, cooking to weight was tried, with very satisfactory results. Tarr and Baker (13) state that jellying occurs when the solution of pectin, represented in this case by fruit extractions, is approximately saturated with respect to sugar - containing between 60 and 70 percent of sugar at $20^{\circ} \mathrm{C}$. Such 


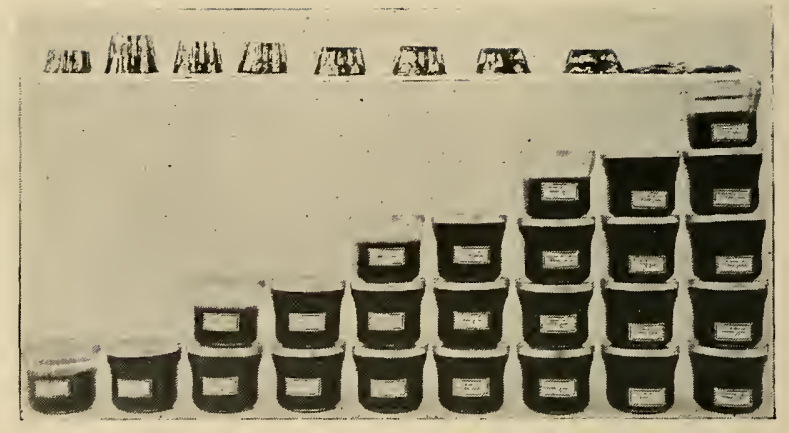

Figure 3.-Effect of Increasing Proportions of Sugar on Consistency and Yicld of Blackberry Jelly from Unripe Fruit. Left to right: Sugar increasing from one-fourth cup to $2 \frac{1}{4}$ cups per cup of juice

a solution should boil between $103^{\circ}$ and $105^{\circ} \mathrm{C}$., which is not far from the actual figures as found for good jellies made from jelly stock in the present experiment. Considering the sugar added at the beginning as remaining unchanged in the final product, the percentage of sugar in a jelly can be found by the following formula:

weight of sugar added

end weight of jelly

$\mathrm{X} 100=$ percentage of sugar in the finished jelly

Similarly, if a satisfactory figure can be established for the percentage of sugar which should obtain in the finished jelly, then this figure can be substituted in the above formula, and the final end weight which the jelly should reach when done can be calculated in advance; thus

weight of sugar added $\times 100=$ end weight that jelly should reach when finished

According to Tarr and Baker (13) the figure for percentage of sugar in the finished jelly is 67.6 to 67.9 for pure pectin solutions; and 69 to 72 for stock pectin solutions, the salts in the unpurified pectin apparently producing the difference. In the present work somewhat lower figures were obtained, due perhaps to a difference in standard used to define "jelly," and also to the fact that purified pectin was not used, but simple water extractions of fruit.

In Table 14 are given the mean figures for percentage of sugar in the end weight of all jellies which scored 80 or above and which formed a true jelly, whether the end point used was "jelly test," temperature, or weight. The figures for jelly made with from 1 to

TABLE 14.-End Weight of Sugar in Jellies

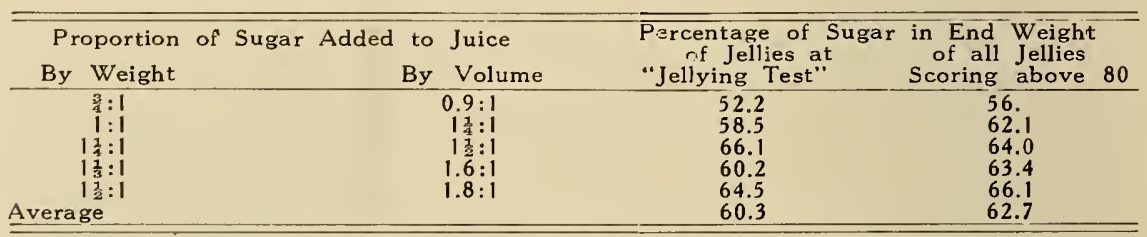


$11 / 2$ parts by weight of sugar to 1 of juice-proportions which produced the best products made-range from 62 to 66 percent; the average, close to 63 percent. Since the coefficient of variation for these figures is approximately 6 percent, they may be considered as expressing a relationship that is fairly definite for the conditions given.

It is interesting to note the close relation between these figures and those for percentage of sugar in jellies at the "jelly point," as determined by the spoon test. Thus (Table 14) for jellies made with 1 to $1 \frac{1}{2}$ parts by weight of sugar, the percentage of sugar in the final weight of jelly varies from 58.5 to 66 percent, as against 62 to 66 percent for the method of cooking to weight.

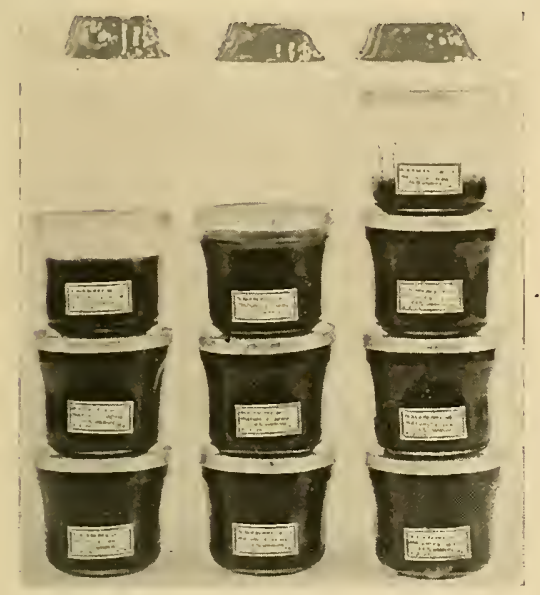

Figure 4.-Consistency and Yield of Blackberry Jelly Made with the Addition of Various Amounts of Unripe Berries. Left to right: 10,15 , and 25 percent unripe berries added Maturity would be expected to affect the jellying power of fruit

The percentage of sugar in the end weight of all true jellies at temperatures between $101^{\circ}$ and $105^{\circ} \mathrm{C}$. is given in Table 15 , which again shows agreement with figures obtained by cooking to weight. This is as close as might be expected from simple extractions of fruit.

Very little difficulty is experienced in cooking to a given end weight. At first, frequent weighings may be necessary, but the appearance of the jelly soon becomes a guide to the proper time to begin weighing. If the weights of the kettle plus end weight of jelly to be reached are left on the platform balance, it is a simple matter to weight the jelly once or twice, and reach the desired end weight within a very small error. in ripe fruit. Jellies were made from both ripe and unripe berries, the effect of ripeness on yield and texture being shown in Figures 1 and 3. In Figure 4 are shown texture and yield of jellies made with the addition of 10,15 , and 25 percent unripe berries. Greater yield is noted as the percentage of unripe berries increases, since the unripe berries will permit the addition of larger amounts of sugar before becoming too soft to set into jelly; and yield is determined by amount of sugar added.

The effect on flavor, however, of increasing amounts of unripe berries will limit their use. The use of from one-tenth to one-fourth of partly ripe blackberries (not green) did not affect flavor unfavorably. Over-ripe berries, being low in acid, would give a $\mathrm{pH}$ outside the range for jellying, and therefore would not yield good jelly. The recommendation that each lot of berries contain some berries still 
showing red gave lots of berries with a range in $\mathrm{pH}$ from 2.97 to 3.17 , all of which yielded good jellies.

A jelly strength tester modeled along the lines of that described by Tarr (14) was used for testing blackberry jellies as they were scored, with the aim of developing a test that would be more reliable than scoring, in which personal opinion plays a large part. Pressure was developed by water running into a siphon bottle from a larger bottle above it. Testing was begun always with water at the same level in the siphon bottle, and the pressure in the siphon was standardized at the beginning, as suggested by Tarr.

Jellies were tested after paraffining, thereby introducing a large source of error,-but one to which jellies submitted for laboratory test would also be subject. Tests were made soon after the jelly was made and again, several months later, on duplicates.

TABLE 15.-Correlation of Temperature with Percentage of Sugar in End Weight

\begin{tabular}{ccc}
\hline \hline & Temperature & Average Percentage of Sugar* \\
101 & 57.5 \\
& 52 & 57.8 \\
& 61.5 \\
& 103 & 64.8 \\
& 104 & 66.1 \\
Average & 105 & 61.5 \\
\hline
\end{tabular}

*6 to 10 trials in each case.

In general, the jelly strength test became higher as the end temperature was increased, and lower after the sugar content was increased to a certain point. More than one-half of the good jellies tested fell between 20 and 40 on the jelly-strength tester, but the remainder showed wide variations on both top and bottom tests. Some of these variations undoubtedly were due to differences in temperature of paraffin as well as to variations in the tester itself. The results were no more accurate in placing a jelly than those based on scoring; and the test consumed considerably more time.

\section{Conclusions}

Blackberries picked while still showing some red color gave extractions having a pH between 2.97 and 3.17 ; all made true jelly.

Good blackberry jelly was made with $1 \frac{1}{4}$ to $1 \frac{1}{2}$ volumes of sugar per volume of juice; the best was made with $11 / 4$ to $11 / 3$ volumes of sugar.

The alcohol test for pectin gave some indication of the amount of sugar which may be added to a given juice for firm jelly.

Temperatures between $102^{\circ}$ and $103^{\circ} \mathrm{C}$. or $216^{\circ}$ and $217^{\circ} \mathrm{F}$. gave the best jellies at 900 feet elevation. Temperatures as high as $105^{\circ} \mathrm{C}$. were satisfactory when the proportion of sugar was optimum.

Cooking jelly to weight, previously determined, in order to yield jelly containing a definite percentage of sugar when finished, offers several advantages over other methods of determining when jelly is finished. The figures giving the best results for all proportions of sugar were 62 to 66 percent.

Addition of some unripe berries increases the yield of jelly but should be limited to 10 to 25 percent of the berries to avoid changes in flavor. 



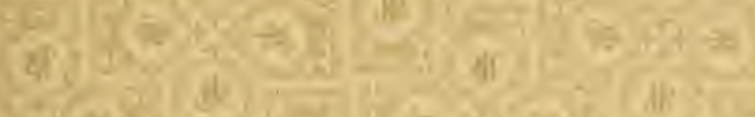

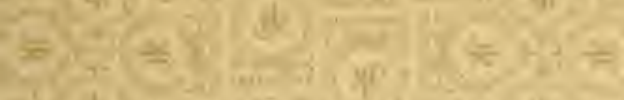

(a)

114

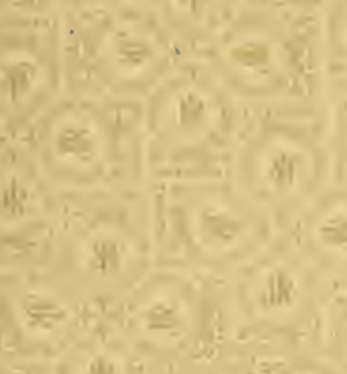

ixan.

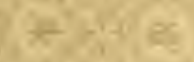

$\left(\frac{1}{16}\right.$

5

D. $10 \% x^{2}, 0$

$\frac{1}{9} \operatorname{lin}^{4}=$

alk

sip

Linas: ${ }^{\circ}$

$\frac{7}{7}+31=$

IV

g1!

Fistes

으.

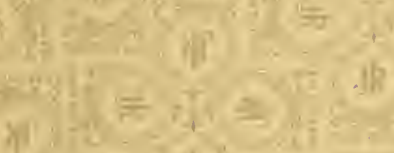

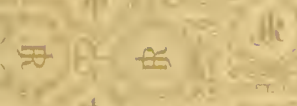
ik

4 $5 \times 3=$

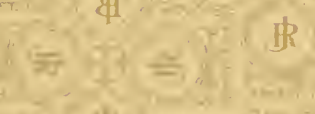

E $84=93$

If

18

ب

$x_{1}=-1$

'

y

ys

R. $(01 \pm=12$

(8) $=$

$\mathfrak{k}$

20.5

मf $-7=$

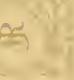

de

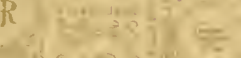

$\mathrm{AP}^{\mathrm{2}} \mathrm{g}, \mathrm{s}$

또

$\mathrm{E}^{\mathrm{N}}+\mathrm{k}^{2} \pm$

ik

IR $\mathrm{H}^{2}$

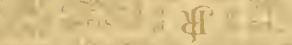

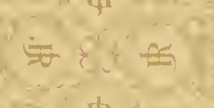

४⿻

R 3 3

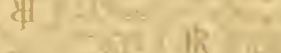

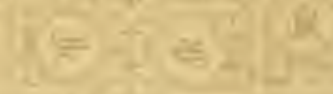

Ir

Wic

in

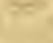

in

xand 71

c

1)

$\frac{7}{4}+1$

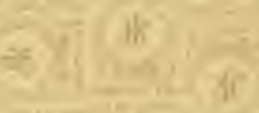

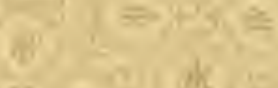

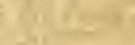

B) $12=$

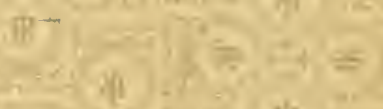

$(68+19=98)$

th

zI'

de 
